\title{
Future Trends in Wireless Sensor Network (WSN)
}

\author{
D.Sridhar Raja , B.Kalaiselvi, T.Vijayan
}

\begin{abstract}
In part years wireless sensor networks (WSNs) have shown great improvement and also have become trusted areas in research. A wireless sensor networks (WSNs) is made up of many wireless sensor nodes that provides the source field and sink of a wireless network. The ability to sense the surrounding nodes, computing and connecting to other nodes wirelessly provide the

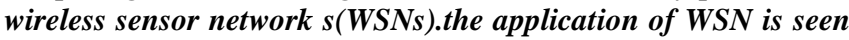
in many areas like military application, tracking, monitoring remote environment, surveillance, healthcare department and so on. Because of wide application the challenges for better developed technology and improvement have increased this paper discuss some of the recent and future trends of Wireless sensor network. [1],[ 3],[5]
\end{abstract}

Keywords : Networks,future application, wireless sensor networks (WSN)

\section{INTRODUCTION}

The recent improvement in MEMS(micro-electromechanical systems) have given more research areas in wireless communication .the compact ness, low cost ,high efficient MEMS devices as made the WSN more advanced area of research, also the processing speed, storing data and sensing have also become more useful in area of WSN. This has made the development in industries application, military application and also in civilian application such as monitoring, controlling and processing.WSN consists of base stations that communicate with other many wireless sensors through RF link between them. The main function of each node in WSN is to collect the data, compress, transmit through other nodes or directly to base station. The basic operation of any WSN to communicate with source and delivery the data to the receiver. The advance in all field of electronics as shown great interest in application in wide range and this paper describes some of the present WSN and future WSN technology along with their challenges[2 ],[ 4],[6]

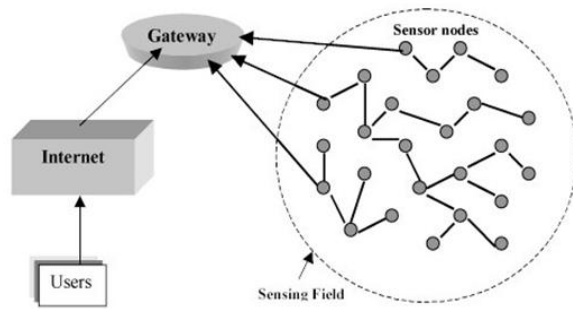

Fig:1

Revised Manuscript Received on August 22, 2019

Sridhar Raja D Department of EIE, Bharath Institute of Higher Education and Research, Tamilnadu, India. Email: sridharraja.eie@bharathuniv.ac.in

B.Kalaiselvi, Department of EIE, Bharath Institute of Higher education and research, Tamilnadu, India. Email: kalaiselvi.eie@bharathuniv.ac.in

T.Vijayan, Department of EIE,Bharath Institute of Higher education and research, Tamilnadu, India. Email: vijayan.eie@bharathuniv.ac.in

\section{ADVANCEMENTS IN WSN}

The advancement in WSN are wide in range due the development of electronics and wireless communication. This as lead to many recent advances in military for surveillance, tracking a target, monitoring health and also monitoring environment etc. Some of advances in various field of WSN is described below along with their application.

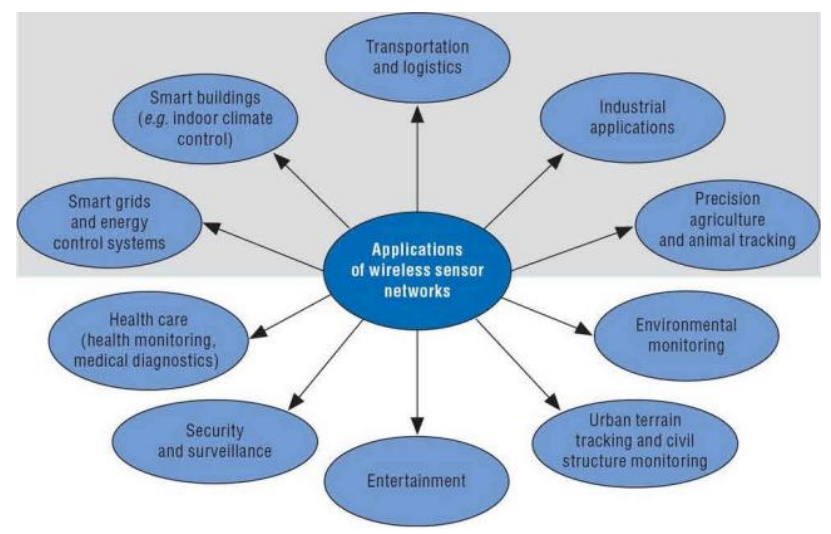

Fig.2 Recent trends in WSN

\section{A. Agriculture}

By deploying WSN in agriculture can give benefit in obtaining information about water requirement and degradation in soil. WSN also helps in water used in irrigation, its amount required by the field and can manage water supply also. [7],[9],[11]

\section{B. Structural inspection}

Structural buildings like heavy bridge, concrete buildings, and composite materials are often inspected for any damages very regular time intervals to replace the damages.by applying WSN in heavy bridges, concrete, buildings etc. also can inspect the damages regularly to prevent very harmful failure. This WSN also reduce the cost of inspecting and maintenance of the structural health for long period.

\section{Monitoring and Control Traffic}

In big cities traffic congestion is one of the main problem faced in entire world.an intelligent system of transport using WSN can provide a complete monitoring of vehicle congestion in traffic roads and automatic control the signals to reduce the conjunction. This process is a real time traffic control where the data is collected every second and processed by the computer involved in this intelligent system. Locating and monitoring a particular vehicle is also possible by WSN. Thus this area as shown much interest in developing WSN and extend its application in intelligent traffic control.

Published By:

Blue Eyes Intelligence Engineering 


\section{Application in Industries}

The main application in industries are flow control, temperature monitoring and control, also pressure control etc. This wireless sensor network as made this process more simple because smart MEMS sensors. Nowadays even small scale industry prepare for WSN because of its effective communication with control unit with low cost. Currently more advanced industry standard micro sensors are developed which with combination with WSN provides a better monitoring and controlling industrial parameters.

\section{E. Defence Applications.}

In military applications the main factor to be considered is the speed, and accuracy of information provided with high security. WSN has provided this factor more reliable then compare to traditional methods the accuracy as improved due to the smart sensors used in WSN, also the speed along development in wireless communication. The application includes to detect chemical threats survillance, secured communication, commanding and control.

\section{F. Smarter Office /Homes}

The next era is of smart homes and smart office where the research is going to turn out; many researches already have done to provide home and offices. Now with the addition of WSN as made this simpler to achieve the goal. WSN will be providing all data collection, communication to provide a complete smart home and office soon at affordable cost by everyone.

\section{G. Developments in Future}

The main future development in WSN is to implement low lost and low power consuming sensor nodes. Also the application to extend in the field of underwater sensor systems, spectrum management, real time applications and security managing. This session briefs some of this in WSN developments

\section{H. Acoustic sensor systems in underwater}

WSN in recent research have been deployed in underwater application but the challenges to be overcome are like mobility of node, propagation delays and every high error in underwater communication is high while compare to land WSNs. This makes the WSNs in underwater more challenging area of research. Once an error free UWSNs protocol is developed numerous application can be done in underwater,few examples are acquiring oceanographic data, monitor pollution in ocean and other water bodies, prevention of disaster in ocean, assisting navigation, surveillance under water, tactical application in underwater defense .along with more sensor in addition natural resources undersea is possible, and collecting scientific information undersea water can be achieved. [8],[10],[12]

\section{Combination with other Networks}

In WSN the sensor nodes play an important role in connection between the source and destination, this sensors are energy dependent.as mentioned above WSN can be used in monitoring health, in Defence, also in building control etc. the collected data can be made more accessible if WSN is connected with other existing networks like LAN, internet, WAN and etc. This interconnection technique between WSN and other network is the future and challenging area for research. [13], [15], [17]

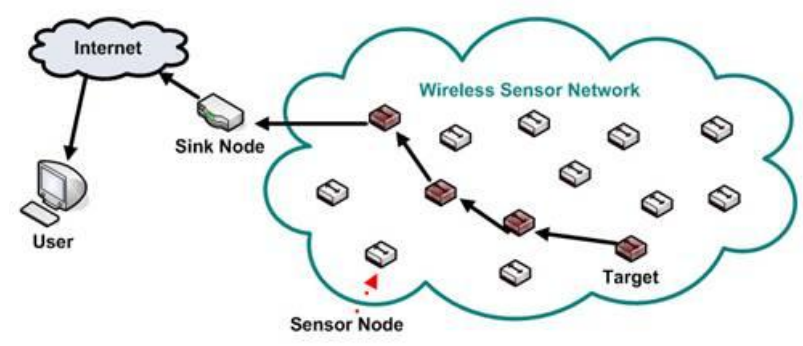

Fig 3. Model of WSN interconnection with internet

\section{J. New application in forest surveillance}

The opportunity of WSN in real time application as open door in different applications one such application is forest environmental surveillance .This application is extended to rural and forest areas to monitor the movements of wildlife also. WSN is also now deployed in forest fire monitoring, ensure the safety of fire fighter, in additiontransportation animals during hazards time. Thus many protocol has been under research area to develop more accurate real time application by WSN. [14],[ 16], [18]

Some research challenges:

Cost of Hardware: here the challenge is in developing compact and low cost WSN for apllication in many field.the solution is MEMS devices which already started to integrated with WAN for few application. [19],[20],[21]

Worldwide protocols: The need of common protocols for entire world as become most important that the communication and application will be available in all parts of world.

Power: In WSN the sensors act as the connecting node and which are power driven, so managing power in WSN system becomes challenging research area.

Similarly there are many challenges in future to avail the full benefit of WSN Worldwide.given below are some other challenges in future WSN.

1. Architecture of WSN systems

2. Security and link trust

3. Analytical and practical problems.

4. Bio medical field,etc.

\section{CONCLUSION}

In many circumstance WSN wirless sensor network is applied such as home,office, defence sector,road traffics,forest,bio medical ,civil engineering etc. This paper discussed about some of the application in traffic, forest, underwater application, healthcare ,monitoring environment ,etc. Also discussed future challenges in developing WSN for entire world application, underwater application, area of research like power management, world wide protocol etc. This paper concludes with the development required in wireless sensor network in future application 


\section{REFERENCES}

[1] Sharma, R.K., Irusapparajan, G. \& Periyaazhagar, D. 2019, "Three-phase symmetric cascading Z-source seven levels multileve inverter excited by multi carrier sinusoidal pulse width modulation scheme", International Journal of Innovative Technology and Exploring Engineering, vol. 8, no. 10, pp. 4269-4274

[2] Velavan, R., Bharanidharan, S. \& Sheeba, B. 2019, "EMF pollution Causes, effects and protection", International Journal of Innovative Technology and Exploring Engineering, vol. 8, no. 9 Special Issue 3, pp. 1166-1168.

[3] Saravana, S., Balaji, S., Arulselvi, S. \& John Paul Praveen, A. 2019, "Reliable power quality monitoring and protection system", International Journal of Innovative Technology and Exploring Engineering, vol. 8, no. 9 Special Issue 3, pp. 644-645.

[4] Tamil Selvan, S. \& Sundararajan, M. 2019, "Performance Parameters of 3 Value 8t Cntfet Based Sram Cell Design Using H-Spice", International Journal of Recent Technology and Engineering, vol. 8, no. 2 Special issue 5, pp. 22-27.

[5] Jac Fredo, A.R., Abilash, R.S., Femi, R., Mythili, A. \& Kumar, C.S. 2019, "Classification of damages in composite images using Zernike moments and support vector machines", Composites Part B: Engineering, vol. 168, pp. 77-86

[6] Kathiravan, P. \& Govindaraju, C. 2019, "Design and evaluation of ultra gain isolated DC-DC converter for photovoltaic system", International Journal of Engineering and Advanced Technology, vol. 8, no. 5, pp. 2646-2651.

[7] Kripa, N., Vasuki, R. \& Kishore Kanna, R. 2019, "Realtime neural interface controlled au-pair BIMA bot", International Journal of Recent Technology and Engineering, vol. 8, no. 1, pp. 992-994.

[8] Mohanraj, Meenaa Kumari, M., Philomina, S. \& Jasmin, M. 2019 , "In-situ humidity measurement of hydrogen fuel cell car using MEMS sensor", International Journal of Recent Technology and Engineering, vol. 8, no. 1, pp. 41-43.

[9] Velmurugan, T. \& Prakash, S. 2019, "Artificial intelligent based distribution automation of swift fault detection isolation and power restoration for HT network", International Journal of Innovative Technology and Exploring Engineering, vol. 8, no. 6, pp. 1-6.

[10] Dwarakesh, K. \& Prem Kumar, G. 2019, "Five-level inverter based sequential boost system using fuzzy logic controller", International Journal of Innovative Technology and Exploring Engineering, vol. 8, no. 6, pp. 12-19.

[11] Anne Gifta, A. \& Hemavathi, G. 2019, "Analysis of grid tied solar PV system using ANFIS Algorithm", International Journal of Innovative Technology and Exploring Engineering, vol. 8, no. 6, pp. 312-316.

[12] Jayavel, R., Rangaswamy, T.R. \& Prakash, S. 2019, "Efficient grid management system with renewable and conventional power sources", International Journal of Innovative Technology and Exploring Engineering, vol. 8, no. 6, pp. 287-289.

[13] Hemavathi, G. \& Maheshwaran, S. 2019, "Proportional resonant controlled high gain step-up converter system with improved response", International Journal of Innovative Technology and Exploring Engineering, vol. 8, no. 6, pp. 317-323.

[14] Periyaazhagar, D. \& Irusapparajan, G. 2019, "Design and completion of asymmetric single phase 27 level cascaded mli for various pwm scheme", International Journal of Innovative Technology and Exploring Engineering, vol. 8, no. 6, pp. 792-797.

[15] Mahalakshmi, V. \& Vijayaragavan, S.P. 2019, "PV based power electronic converters for high voltage DC applications", International Journal of Recent Technology and Engineering, vol. 7, no. 6, pp. 670-674.

[16] Irusapparajan, G., Periyaazhagar, D., Prabaharan, N. \& Rini Ann Jerin, A. 2019, "Experimental verification of trinary DC source cascaded h-bridge multilevel inverter using unipolar pulse width modulation", Automatika, vol. 60, no. 1, pp. 19-27.

[17] Sangeetha, G., Sherine, S., Arputharaju, K. \& Prakash, S. 2019, "On Line Monitoring of Higher Rated Alternator using Automated Generator Capability Curve Administer", Proceedings of the IEEE International Conference on \&amp;quot;Recent Trends in Electrical, Control and Communication\&amp;quot;, RTECC 2018, pp. 176.

[18] Bycil, V.J. \& Wiselin, M.C.J. 2019, "Modeling and analysis of vibration energy harvesting system using piezo stack", International Journal of Mechanical and Production Engineering Research and Development, vol. 9, no. Special Issue 1, pp. 523-533.

[19] Sripada, A., Warrier, A., Kapoor, A., Gaur, H. \& Hemalatha, B. 2018, "Dynamic lateral balance of humanoid robots on unstable surfaces", International Conference on Electrical, Electronics, Communication
Computer Technologies and Optimization Techniques, ICEECCOT 2017, pp. 539

20] Srinivasan, S., Thirumalaivasan, K. \& Sivakumaran, T.S. 2018 , "Performance evaluation of double-output luo converters", Journal of Advanced Research in Dynamical and Control Systems, vol. 10, no. 10 Special Issue, pp. 870-878.

[21] Karthikayen, A. \& Selvakumar Raja, S. 2018, "A skellam distribution inspired trust factor-based selfish node detection technique in MANETs", Journal of Advanced Research in Dynamical and Control Systems, vol. 10, no. 13, pp. 940-949.

\section{AUTHORS PROFILE}

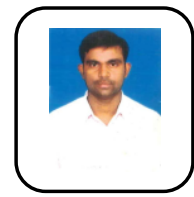

Sridhar raja D, Assistant Professor, Department of EIE,Bharath Institute of Higher education and research, Tamilnadu, India.

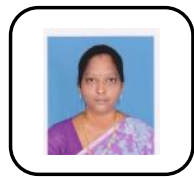

B.Kalaiselvi, Assistant Professor, Department of EIE,Bharath Institute of Higher education and research, Tamilnadu, India

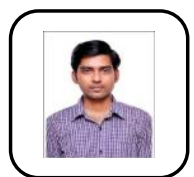

T.Vijayan, Assistant Professor, Department of EIE,Bharath Institute of Higher education and research, Tamilnadu, India. 